УДК 541.64

ББК 886

\title{
THE REINFORCEMENT OF PARTICULATE-FILLED POLYMER NANOCOMPOSITES BY NANOPARTICLES AGGREGATES
}

\author{
Georgiy Vladimirovich Kozlov
}

\author{
Senior Researcher, \\ Kabardino-Balkarian State University named after H.M. Berbekov \\ I_dolbin@mail.ru \\ Chernyshevskogo St., 175, 360004 Nalchik, Russian Federation
}

\section{Abdullah Kasbulatovich Mikitaev}

\author{
Doctor of Chemical Sciences, Professor, \\ Kabardino-Balkarian State University named after H.M. Berbekov \\ I_dolbin@mail.ru \\ Chernyshevskogo St., 175, 360004 Nalchik, Russian Federation
}

\begin{abstract}
The applicability of irreversible aggregation model for theoretical description of nanofiller particles aggregation process in polymer nanocomposites has been shown. The main factors, influencing nanoparticles aggregation process, were revealed. It has been shown that strongly expressed particulate nanofiller particles aggregation results in sharp (in about 4 times) formed fractal aggregates real elasticity modulus reduction. Nanofiller particles aggregation is realized by cluster-cluster mechanism and results in the formed fractal aggregates density essential reduction, that is the cause of their elasticity modulus decrease. As distinct from microcomposites, nanocomposites require consideration of interfacial effects for elasticity modulus correct description in virtue of a well-known large fraction of phases division surfaces for them.
\end{abstract}

Key words: nanocomposite, globular nanocarbon, calcium carbonate, aggregation, interfacial effects, reinforcement.

\section{Introduction}

In the course of technological process of particulate-filled polymer composites in general [19] and nanocomposites $[1 ; 8]$ in particular, preparation of the initial filler powder particles aggregation in more or less large particles aggregates always occurs. The aggregation process exercises essential influence on composites (nanocomposites) macroscopic properties $[1 ; 3 ; 8 ; 10 ; 15 ; 19]$. For nanocomposites (2) the aggregation process gains special significance, since its intensity can be such, that nanofiller particles aggregates size exceeds $100 \mathrm{~nm}$ - the value, which is assumed (although conditionally enough [6]) as upper dimensional limit for a nanoparticle. In other words, the aggregation process can result in the situation, when initially supposed nanocomposite ceases to be such. Therefore at present a number of methods exists, allowing to suppress nanoparticles aggregation process $[13 ; 15]$.

Analytically this process is treated as follows. The authors [5] obtain the relationship: 


$$
k(r)=7.5 \times 10^{-3} S_{u},
$$

where $k(r)$ is aggregation parameter, $S_{u}$ is specific surface of nanofiller initial particles, which is given in $\mathrm{m}^{2} / \mathrm{g}$.

In its turn, the value $S_{u}$ is determined as follows [7]:

$$
S_{u}=\frac{6}{\rho_{n} D_{p}},
$$

where $\rho_{n}$ is nanofiller density, $D_{p}$ is diameter of its initial particles.

From the equations (1) and (2) it follows, that $D_{p}$ reduction results in $S_{u}$ growth, that in its turn reflects in the aggregation intensification, characterized by the parameter $k(r)$ increasing. Therefore in polymer nanocomposites strengthening (reinforcing) element are not nanofiller initial particles themselves, but their aggregates [2]. This results in essential changes of nanofiller elasticity modulus, the value of which is determined with the aid of the equation [2]:

$$
E_{\text {agr }}=E_{\text {nan }}\left(\frac{a}{R_{\text {agr }}}\right)^{3+d_{l}},
$$

where $E_{\text {agr }}$ is nanofiller particles aggregate elasticity modulus, $E_{\text {nan }}$ is elasticity modulus of material, from which the nanofiller was obtained, $a$ is an initial nanoparticles size, $R_{\text {agr }}$ is a nanoparticles aggregate radius, $d_{l}$ is chemical dimension of the indicated aggregate, which is equal to $\sim 1.1$ [2].

As it follows from the equation (3), the initial nanoparticles aggregation degree enhancement, expressed by $R_{\text {agr }}$ growth, results in $E_{\text {agr }}$ decrease (the rest of parameters in the equation (3) are constant) and, as consequence, in nanocomposite elasticity modulus reduction.

Very often the elasticity modulus (or reinforcement degree) of polymer composites (nanocomposites) is described within the frameworks of numerous micromechanical models, which proceed from elasticity modulus of matrix polymer and filler (nanofiller) and the latter volume contents [1]. Additionally it is supposed, that the indicated above characteristics of a filler are approximately equal to the corresponding parameters of compact material, from which a filler is prepared. This practice is inapplicable absolutely in case of polymer nanocomposites with fine-grained nanofiller, since in this case a polymer is reinforced by nanofiller fractal aggregates, whose elasticity modulus and density differ essentially from compact material characteristics (see the equation (3)) $[17 ; 21]$. Therefore the microcomposite models application, as a rule, gives a large error at polymer composites elasticity modulus evaluation, that in its turn results in the appearance of an indicated models modifications large number [12].

Proceeding from the said above, the present work purpose is the theoretical treatment of particulate nanofiller aggregation process and elasticity modulus (reinforcement degree) particulatefilled polymer nanocomposites with due regard for the indicated effect within the framework of irreversible aggregation models and fractal analysis.

\section{Experimental}

Polypropylene (PP) "Kaplen" of mark 01030 with average weight molecular mass of $\sim(2-3) \times 10^{3}$ and polydispersity index 4.5 was used as matrix polymer. Nanodimensional calcium carbonate $\left(\mathrm{CaCO}_{3}\right)$ in compound form of mark Nano-Cal P-1014 (production of China) with particles size of $80 \mathrm{~nm}$ and mass contents of 1-7 mass. \% and globular nanocarbon (GNC) (production of corporations group "United Systems", Moscow, Russian Federation) with particles size of 5-6 nm, specific surface of $1400 \mathrm{~m}^{2} / \mathrm{g}$ and mass contents of 0.25-3.0 mass. \% were applied as nanofiller.

Nanocomposites $\mathrm{PP} / \mathrm{CaCO}_{3}$ and $\mathrm{PP} / \mathrm{GNC}$ were prepared by components mixing in melt on a twin screw extruder Thermo Haake, model Reomex RTW 25/42, production of German Federal Republic. Mixing was performed at temperature 463-503 K and screw speed of $50 \mathrm{rpm}$ during $5 \mathrm{~min}$. Testing samples were prepared by casting under pressure method on a casting machine Test Sample Molding Apparatus RR/TS MP of firm Ray-Ran (Taiwan) at temperature $483 \mathrm{~K}$ and pressure $43 \mathrm{MPa}$.

The nanocomposites melt viscosity was characterized by a melt flow index (MFI). MFI measurements were performed on an extrusion-type plastometer Noselab ATS A-MeP (production of Italy) with capillary diameter of $2.095 \pm 0.005 \mathrm{~mm}$ at temperature $513 \mathrm{~K}$ and load of $2.16 \mathrm{~kg}$. The sample was maintained at the indicated temperature during $4.5 \pm 0.5 \mathrm{~min}$. 
Uniaxial tension mechanical tests have been performed on the samples in the shape of a two-sided spade with sizes according to GOST $11262-80$. The tests have been conducted on a universal testing apparatus Gotech Testing Machine CT-TCS 2000, production of German Federal Republic, at temperature $293 \mathrm{~K}$ and strain rate $\sim 2 \times 10^{-3} \mathrm{~s}^{-1}$.

\section{Results and Discussion}

The particulate nanofiller aggregation degree can be evaluated and aggregates diameter $D_{\text {agr }}$ quantitative estimation can be performed within the framework of strength dispersive theory [9], where shear yield stress of nanocomposite $\tau_{n}$ is determined as follows:

$$
\tau_{n}=\tau_{m}^{\prime}+\frac{G_{n} b_{B}}{\lambda},
$$

where $\tau_{m}$ is shear yield stress of polymer matrix, $b_{B}$ is Burgers vector, $G_{n}$ is nanocomposite shear modulus, $\lambda$ is distance between nanofiller particles.

In case of nanofiller particles aggregation the equation (4) has the look [9]:

$$
\tau_{n}=\tau_{m}^{\prime}+\frac{G_{n} b_{B}}{k(r) \lambda},
$$

where $k(r)$ is aggregation parameter.

The parameters, included in the equations (4) and (5) are determined as follows. The general relationship between normal stress $\sigma$ and shear stress $\tau$ has the look [4]:

$$
\tau=\frac{\sigma}{\sqrt{3}} .
$$

The intercommunication of matrix polymer $\tau_{m}$ and nanocomposite polymer matrix $\tau_{m}^{\prime}$ shear yield stresses is given as follows [5]:

$$
\tau_{m}^{\prime}=\tau_{m}\left(1-\varphi_{n}^{2 / 3}\right),
$$

where $\varphi_{n}$ is nanofiller volume content, which can be determined according to the well-known formula [5]:

$$
\varphi_{n}=\frac{W_{n}}{\rho_{n}},
$$

where $W_{n}$ is nanofiller mass contents, $\rho_{n}$ is its density, which for nanoparticles is determined according to the equation [5]:

$$
\rho_{n}=188\left(D_{p}\right)^{1 / 3}, \mathrm{~kg} / \mathrm{m}^{3},
$$

where $D_{p}$ is given in $\mathrm{nm}$.

The value of Burgers vector $b_{B}$ for polymeric materials is determined as follows [3]:

$$
b_{B}=\left(\frac{60.5}{C_{\infty}}\right)^{1 / 2}, \AA,
$$

where $C_{\infty}$ is characteristic ratio, connected with nanocomposite structure dimension $d_{f}$ by the equation [3]:

$$
C_{\infty}=\frac{2 d}{d(d-1)\left(d-d_{f}\right)}+\frac{4}{3},
$$

where $d$ is dimension of Euclidean space, in which a fractal is considered (it is obvious, that in our case $d=3$ ).

The value $d_{f}$ can be calculated according to the equation [11]:

$$
d_{f}=(d-1)(1+v),
$$

where $v$ is Poisson's ratio, estimated according to the mechanical tests results with the aid of the relationship [10]:

$$
\frac{\sigma_{Y}}{E_{n}}=\frac{1-2 v}{6(1+v)},
$$

where $\sigma_{Y}$ and $E_{n}$ are yield stress and elasticity modulus of nanocomposite, respectively.

Nanocomposite moduli $E_{n}$ and $G_{n}$ are connected between themselves by the relationship [1]:

$$
C_{n}=\frac{E_{n}}{d_{f}} .
$$

And at last, the distance $\lambda$ between nanofiller nonaggregated particles is determined according to the equation [19]:

$$
\lambda=\left[\left(\frac{4 \pi}{3 \varphi_{n}}\right)-2\right] \frac{D_{p}}{2} .
$$

From the equations (5) and (15) $k(r)$ growth from 5.65 up to 43.70 within the range of $W_{n}=0.25$ 3.0 mass. $\%$ for nanocomposites $\mathrm{PP} / \mathrm{GNC}$ and from 1.0 up to 2.87 within the range of $W_{n}=1-7$ mass. $\%$ for nanocomposites $\mathrm{PP} / \mathrm{CaCO}_{3}$ follows. Let us note, that the indicated variation $k(r)$ for the considered 
nanocomposites corresponds completely to the equations (1) and (2). Let us consider, how such $k(r)$ growth is reflected on nanofiller particles aggregates diameter $D_{\text {agr }}$. The equations (8), (9) and (15) combination gives the following relationship:

$$
k(r) \lambda=\left[\left(\frac{0.251 \pi D_{\mathrm{agr}}^{1 / 3}}{W_{n}}\right)^{1 / 3}-2\right] \frac{D_{\mathrm{agr}}}{2},
$$

allowing at $D_{p}$ replacement on $D_{\text {agr }}$ to determine real, i. e. with accounting of nanofiller particles aggregation, nanoparticles aggregates diameter of the used nanofiller. Calculation according to the equation (16) shows $D_{\text {agr }}$ increasing (corresponding to $k(r)$ growth) from 25 up to $125 \mathrm{~nm}$ within the range of $W_{n}=0.25-3.0$ mass. \% for GNC and from 80 up to $190 \mathrm{~nm}$ within the range of $1-7$ mass. \% for $\mathrm{CaCO}_{3}$. Further nanofiller particles aggregates density can be calculated according to the equation (9) at the condition of $D_{p}$ replacement by $D_{\text {agr }}$.

Within the framework of irreversible aggregation model $D_{\text {agr }}$ value is given by the following relationship [20]:

$$
D_{\text {agr }} \sim\left(\frac{4 c_{0} k T}{3 \eta m_{0}}\right)^{1 / d_{f}^{\mathrm{agr}}} t^{1 / d_{f}^{\mathrm{agr}}}
$$

where $c_{0}$ is nanoparticles initial concentration, $k$ is Boltzmann constant, $T$ is temperature, $\eta$ is medium viscosity, $m_{0}$ is mass of initial nanoparticle, $d_{f}^{\text {agr }}$ is fractal dimension of particles aggregate, $t$ is aggregation process duration.

Let us consider estimation methods of the parameters, included in the relationship (17). In the simplest case it can be accepted that all particles of nanofiller initial powder have the same size and mass. In this case $c_{0} \approx \varphi_{n}$, where $\varphi_{n}$ value is determined according to the equation (8) with using nanofiller particles aggregates diameter $D_{\text {agr }}$. $\eta$ value is accepted equal to reciprocal of MFI value and $m_{0}$ magnitude was calculated as follows. In supposition of nanofiller initial particles spherical shape the nanoparticle volume was calculated according to the known values of their diameter $D_{p}$ and then, using $\rho_{n}$ value, calculated according to the equation (8), their mass $m_{0}$ can be estimated. $T$ value is accepted as constant and equal to nanocomposites processing duration, i. e. $300 \mathrm{~s}$.

The fractal dimension of nanofiller particles aggregates structure $d_{f}^{\text {agr }}$ was calculated with the aid of the equation [17]:

$$
\rho_{n}=\rho_{\text {dens }}\left(\frac{D_{\text {agr }}}{2 a}\right)^{d_{f}^{\text {agr }}-d},
$$

where $\rho_{\text {dens }}$ is density of compact material of nanofiller particles, $a$ is self-similarity (fractality) lower scale of nanofiller particles aggregates.

$\rho_{\text {dens }}$ value for carbon is accepted equal to $2700 \mathrm{~kg} / \mathrm{m}^{2}$, for $\mathrm{CaCO}_{3}-2000 \mathrm{~kg} / \mathrm{m}^{2}$ [17] and $a$ value is accepted equal to the initial GNC particle radius, i. e. $2.5 \mathrm{~nm} . d_{f}^{\text {agr }}$ values, calculated according to the equation (18), are equal to 2.092.67 and 2.47-2.75 for $\mathrm{GNC}$ and $\mathrm{CaCO}_{3}$ nanoparticles aggregates, respectively.

In Fig. 1 the dependences $D_{\text {agr }}\left(W_{n}\right)$, plotted according to the equations (16) and (17), comparison is adduced. As one can see, the good enough correspondence of estimations according to both indicated methods was obtained (the average discrepancy of $D_{\text {agr }}$ values, calculated with the usage of these relationships, makes up $\sim 16 \%$ ). This circumstance indicates, that irreversible aggregation models can be used for the theoretical description of particulate nanofiller particles aggregation processes. Besides, the equation (17) analysis demonstrates various factors influence on nanofiller particles aggregates size (or their aggregation degree). So, $c_{0}, T$ and $t$ increasing results in aggregation processes intensification and $\eta, m_{0}$ and $d_{f}^{\text {agr }}$ enhancement - to their weakening.

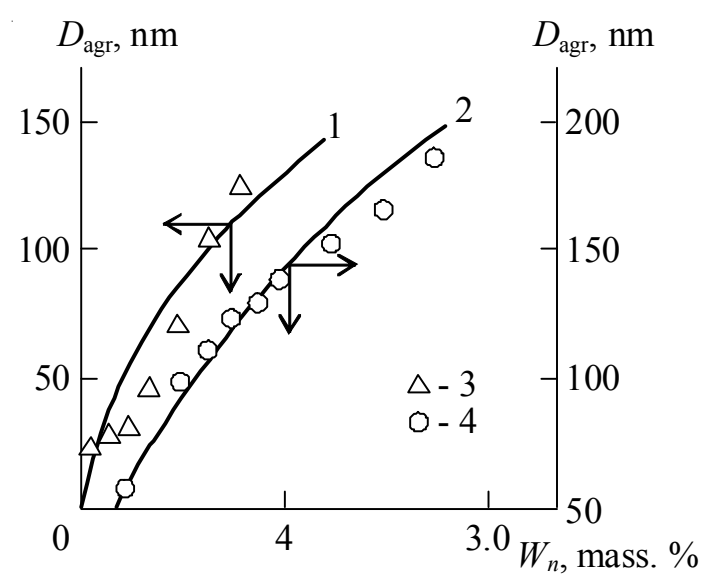

Fig. 1. The dependences of nanofiller particles aggregates diameter $D_{\text {agr }}$ on nanofiller mass contents $W_{n}$ for nanocomposites $\mathrm{PP} / \mathrm{GNC}(1,3)$ and $\mathrm{PP} / \mathrm{CaCO}_{3}(2,4)$ :

1,2 - calculation according to the equation (16);

3,4 - calculation according to therelationship (17)

Let us note in conclusion, that proportionality coefficient in the relationship (17) 
for $\mathrm{GNC}$ and $\mathrm{CaCO}_{3}\left(c_{\mathrm{GNC}}\right.$ and $c_{\mathrm{CaCO}_{3}}$, respectively) can be approximated by the following relationship:

$$
\frac{c_{\mathrm{CaCO}_{3}}}{c_{\mathrm{GNC}}}=\left(\frac{m_{0}^{\mathrm{CaCO}_{3}}}{m_{0}^{\mathrm{GNC}}}\right)^{1 / d_{f}^{a v}},
$$

where $m_{0}^{\mathrm{CaCO}_{3}}$ and $m_{0}^{\mathrm{CNC}}$ are masses of the initial particles of $\mathrm{CaCO}_{3}$ and $\mathrm{GNC}$, respectively, $d_{f}^{a v}$ is average fractal dimension of the indicated nanoparticles aggregates.

Further elasticity modulus $E_{\text {agr }}$ of nanofiller particles aggregates according to the equation (3) can be determined. Let us consider the concrete conditions of this equation usage in reference to nanocomposites $\mathrm{PP} / \mathrm{GNC}$. Two possible variants exist at parameter $a$ choice in the indicated equation. The first implies, that the value $a$ is equal to GNC initial particles diameter [21], i. e. $5.5 \mathrm{~nm}$. Such supposition means, that GNC nanoparticles aggregates are formed by particle-cluster $(\mathrm{P}-\mathrm{Cl})$ mechanism, i. e. by separate particles GNC joining a growing aggregate [18]. However, such supposition gives unreally high $E_{\text {agr }}$ values of order of $5 \times 10^{5} \mathrm{GPa}$. The other variant assumes, that nanofiller aggregation is realized by a clustercluster $(\mathrm{Cl}-\mathrm{Cl})$ mechanism, i. e. small clusters association in larger ones [18]. In such model aggregate radius $R_{\text {agr }}^{i-1}$ on the previous $(i-1)$ aggregation stage is accepted as $a$ and then the equation (3) can be rewritten as follows:

$$
E_{n}=E_{\mathrm{agr}}\left(\frac{R_{\mathrm{agr}}^{i-1}}{R_{\mathrm{agr}}^{i}}\right)^{4.1} .
$$

The elasticity modulus $E_{\text {agr }}$ real values within the range of 21.3-5.0 GPa were obtained at such calculation method. Further the simplest microcomposite models can be used for nanocomposite elasticity modulus $E_{n}$ estimation. For the case of uniform strain in nanocomposite phases the theoretical value $E_{n}\left(E_{n}^{T}\right)$ is given by a parallel model [1]:

$$
E_{n}^{T}=E_{\text {agr }} \varphi_{n}+E_{m}\left(1-\varphi_{n}\right),
$$

where $E_{m}$ is elasticity modulus of matrix polymer.

For the case of uniform stress in nanocomposite phases the lower theoretical boundary $E_{n}^{T}$ is determined according to the serial model [1]:

$$
E_{n}^{T}=\frac{E_{\mathrm{agr}} E_{m}}{E_{\mathrm{agr}}\left(1-\varphi_{n}\right)+E_{m} \varphi_{n}} .
$$

In Fig. 2 the comparison of the received experimentally $E_{n}$ and calculated according to the equations (21) and (22) $E_{n}^{T}$ elasticity modulus values of the considered nanocomposites PP/GNC is adduced. As one can see, the experimental data correspond better to the determined according to the equation (21) $E_{n}^{T}$ upper boundary (in this case average discrepancy of $E_{n}$ and $E_{n}^{T}$ makes up $\sim 8 \%$ ). The indicated discrepancy is due to objective causes. As it is known [1], at the equations (21) and (22) derivation the equality of Poisson's ratio for nanocomposite both phases was supposed. In practice this condition non-fulfillment defines discrepancy between experimental and theoretical data.

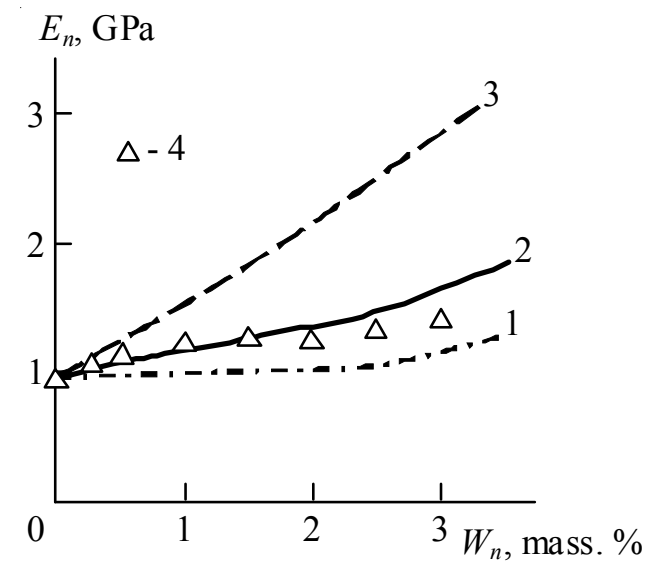

Fig. 2. The dependences of elasticity modulus $E_{n}$ on nanofiller mass contents $W_{n}$ for nanocomposites PP/GNC:

1 - calculation according to the equation (22);

2 - according to the equation (21) at $E_{\text {agr }}=$ variant; 3 - according to the equation (21)

at $E_{\text {agr }}=$ const $=21.3 \mathrm{GPa} ; 4-$ experimental data

In Fig. 2 the dependence $E_{n}^{T}\left(W_{n}\right)$, calculated according to the equation (21) in supposition $E_{\text {agr }}=$ const $=21.3 \mathrm{GPa}$, is also adduced. As one can see, in this case the theoretical values of elasticity modulus $E_{n}^{T}$ exceed essentially experimentally received ones $E_{n}$. Hence, the good correspondence of experiment and calculation according to the equation (21) is due to real values $E_{\text {agr }}$ usage only.

It is obvious, that nanoparticles aggregates elasticity modulus reduction is due to the indicated aggregates diameter growth and, as consequence, 


\section{ТЕХНИКО-ТЕХНОЛОГИЧЕСКИЕ ИННОВАЦИИ}

their density $\rho_{n}$ reduction, which can be calculated according to the equation (18). In Fig. 3 the dependence $E_{\text {agr }}\left(\rho_{n}\right)$ is adduced, which, as was expected, proves to be linear, passing through coordinates origin and is described analytically by the following empirical equation:

$$
E_{\text {agr }}=12.6 \times 10^{-3} \rho_{n}, \mathrm{GPa},
$$

where $\rho_{n}$ is given in $\mathrm{kg} / \mathrm{m}^{3}$.

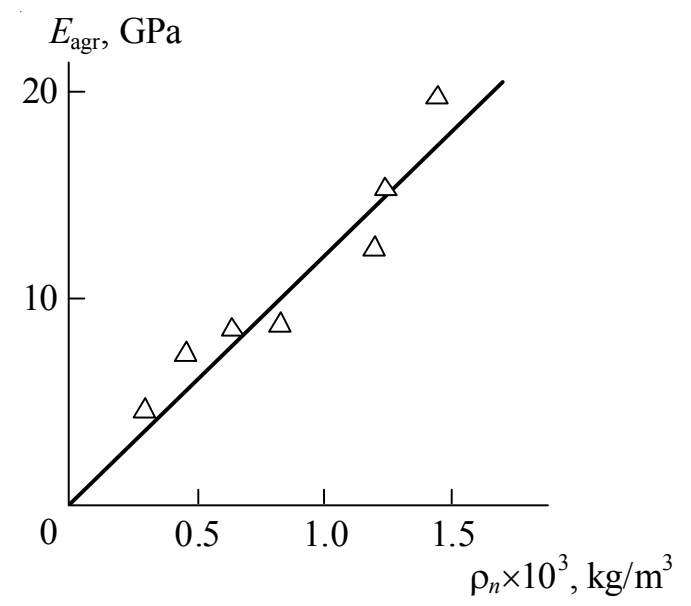

Fig. 3. The dependence of GNC nanoparticles fractal aggregates elasticity modulus $E_{\text {agr }}$ on their density $\rho_{n}$ for nanocomposites PP/GNC

The limiting magnitude $\rho_{n}=\rho_{\text {dens }}$ allows to obtain the greatest value $E_{\mathrm{agr}} \approx 34 \mathrm{GPa}$ for GNC aggregates, that is the real value of this parameter [12].

The authors [9] proposed to use for nanocomposites elasticity modulus $E_{n}$ determination a modified mixtures rule, which in original variant gives upper limiting value of composites elasticity modulus [1]:

$$
E_{n}=E_{m}\left(1-\varphi_{n}\right)+b E_{\mathrm{nan}} \varphi_{n},
$$

where $b<1$ is coefficient, reflecting nanofiller properties realization degree in polymer nanocomposite. In the present work the parameter $b E_{\text {nan }}$ as a matter of fact presents nanofiller effective modulus or, more precisely, its aggregates modulus $E_{\text {agr }}$ (compare with the equation (21)).

In Fig. 4 the dependence of parameter $b$ in the equation (24) on nanofiller particles aggregates diameter $D_{\text {agr }}$, calculated according to the equation (16), for the studied nanocomposites is adduced. As one can see, this dependence disintegrates on two linear parts: at small $D_{\text {agr }}$ fast decay of $b$ at $D_{\text {agr }}$ growth is observed and at large enough $D_{\text {agr }}$ the value $b \approx$ const $\approx 0.175$. Let us note that dimensional interval of the indicated transition, shown in Fig. 4 by a shaded area, makes up $D_{\text {agr }} \approx 70-100 \mathrm{~nm}$, i. e. it coincides approximately with upper dimensional boundary of nanoparticles interval (although a conditional one [6]), which is equal to about $100 \mathrm{~nm}$. As a matter of fact, the indicated dimensional interval defines the transition from nanocomposites to microcomposites, the dependence $b\left(D_{\text {agr }}\right)$ for which differs actually qualitatively. The adduced in Fig. 4 dependence $b\left(D_{\text {agr }}\right)$ can be described analytically by the following integrated equation:

$$
\begin{gathered}
b=0.67-6.7 \times 10^{-3} D_{\text {agr }}, \text { for } D_{\text {agr }} \leq 70 \mathrm{~nm}, \\
b=\text { const }=0.175, \text { for } D_{\text {agr }}>70 \mathrm{~nm} .
\end{gathered}
$$

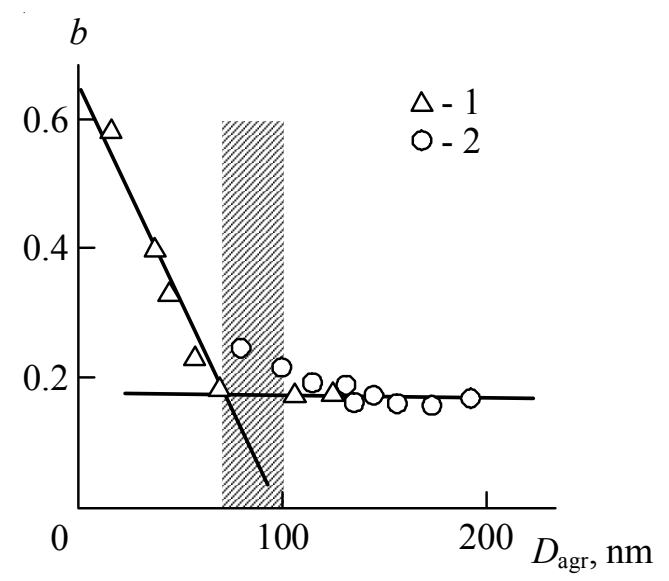

Fig. 4. The dependence of parameter $b$ on nanofiller particles aggregates diameter $D_{\text {agr }}$ for nanocomposites PP/GNC (1) and PP/CaCO ${ }_{3}(2)$. The shaded area indicates transition of nanofiller particles aggregates from nano- to microbehavior

In Fig. 5 the comparison of experimentally obtained and calculated according to the equation (25) dependences $E_{n}\left(\varphi_{n}\right)$ is adduced for the studied nanocomposites. In this case the parameter $b$ value was estimated according to the equation (25) and values $E_{\text {nan }}$ were accepted equal to $30 \mathrm{GPa}$ for $\mathrm{GNC}$ and $15 \mathrm{GPa}$ for $\mathrm{CaCO}_{3}$. As one can see, the good correspondence of theory and experiment is obtained (their mean discrepancy makes up $3 \%$, that approximately equal to the experimental error of $E_{n}$ determination). Higher values $E_{n}$ for nanocomposites $\mathrm{PP} / \mathrm{GNC}$ in comparison with $\mathrm{PP} /$ 
$\mathrm{CaCO}_{3}$ even at $D_{\text {agr }}>100 \mathrm{~nm}$ are due to two factors: the initial nanoparticles of smaller size, that give higher values $\varphi_{n}$ at the same $W_{n}$ values (see the equations (8) and (9)) and higher value $E_{\text {nan. }}$. It is important to note close values $E_{\text {agr }}$ for nanocomposites $\mathrm{PP} / \mathrm{GNC}$, determined according to the equation (20) and as $b E_{\text {nan }}$.

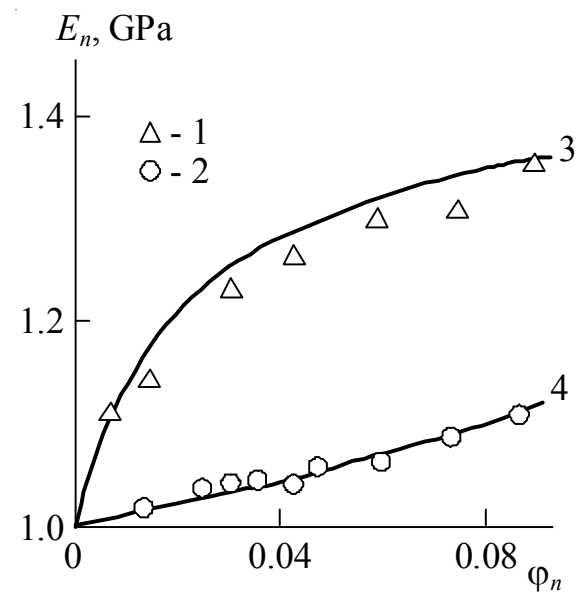

Fig. 5. The comparison of experimentally received $(1,2)$ and calculated according to the equations (24) and $(25)(3,4)$ dependences of elasticity modulus $E_{n}$ on nanofiller volume contents $\varphi_{n}$ for nanocomposites $\mathrm{PP} / \mathrm{GNC}(1,3)$ and $\mathrm{PP} / \mathrm{CaCO}_{3}(2,4)$

The authors [4] proposed the following percolation relationship for polymer microcomposites reinforcement degree $E_{c} / E_{m}$ description:

$$
\frac{E_{c}}{E_{m}}=1+11\left(\varphi_{n}\right)^{1 / 7}
$$

where $E_{c}$ is elasticity modulus of microcomposite.

Later the relationship (26) was modified in reference to the polymer nanocomposites case [16]:

$$
\frac{E_{n}}{E_{m}}=1+11\left(\varphi_{n}+\varphi_{i f}\right)^{1.7}
$$

where $\varphi_{i f}$ is relative fraction of interfacial regions.

It is easy to see, that the modified relationship (27) takes into consideration a factor of sharp increase of division surfaces polymer matrix-nanofiller [2]. In Fig. 6 the comparison of experimentally obtained and calculated according to the equation (26) dependences $E_{n}\left(\varphi_{n}\right)$ for the considered nanocomposites is adduced. As it follows from this figure data, the equation (26) describes well the experimental data for nanocomposites $\mathrm{PP} /$ $\mathrm{CaCO}_{3}$, but the corresponding data for nanocomposites $\mathrm{PP} / \mathrm{GNC}$ set essentially higher than theoretical curve. This discrepancy cause is obvious from the equations (26) and (27) comparison - for nanocomposites $\mathrm{PP} / \mathrm{GNC}$ interfacial effects accounting is necessary, i. e. parameter $\varphi_{i f}$ accounting. Hence, in the considered case only compositions $\mathrm{PP} / \mathrm{GNC}$ are true nanocomposites.

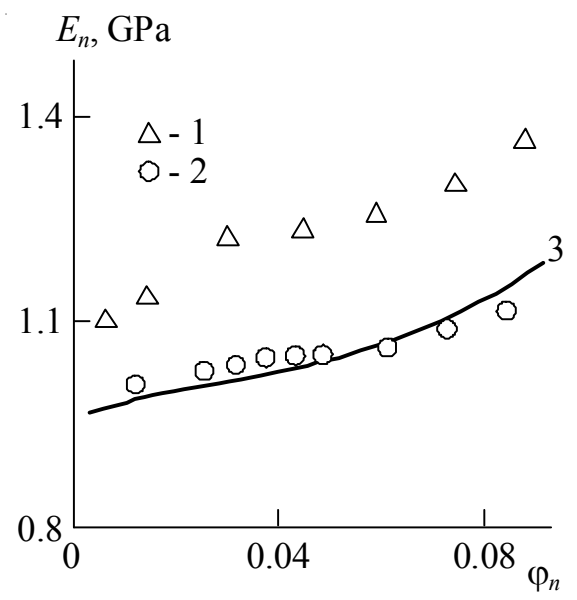

Fig. 6. The comparison of experimentally received $(1,2)$ and calculated according to the equations (26) (3) dependences of elasticity modulus $E_{n}$ on nanofiller volume contents $\varphi_{n}$ for nanocomposites $\mathrm{PP} / \mathrm{GNC}(1,3)$ and $\mathrm{PP} / \mathrm{CaCO}_{3}(2,4)$

\section{Conclusions}

The applicability of irreversible aggregation models for theoretical description of particulate nanofiller particles aggregation processes in polymer nanocomposites has been shown. Analysis within the framework of the indicated models allows to reveal the influence of factors on aggregation degree.

Strongly expressed aggregation of particulate nanofiller particles results in sharp (in about 4 times) formed fractal aggregates real elasticity modulus reduction. In its turn, this process defines nanocomposites as the whole elasticity modulus reduction. Nanofiller particles aggregation is realized by a cluster-cluster mechanism and results in the formed fractal aggregates density essential reduction, that is the cause of their elasticity modulus decreasing.

A nanofiller elastic properties realization degree is defined by the aggregation of its initial particles level. Unlike microcomposites, 


\section{ТЕХНИКО-ТЕХНОЛОГИЧЕСКИЕ ИННОВАЦИИ}

nanocomposites require interfacial effects accounting for elasticity modulus correct description in virtue of well-known large fraction of phases division surfaces for them.

\section{REFERENCES}

1. Ahmed S., Jones F.R. Reinforcement of Rubber by Fractal Aggregates. J. Mater. Sci., 1990, vol. 25, no. 12, pp. 4933-4942.

2. Andrievsky R.A. Nanomaterialy: Kontseptsiya i Sovremennye Problemy. Russian Chemical Journal, 2002, vol. 46, no. 5, pp. 50-56.

3. Balankin A.S. Synergetics of Deformable Body. Moscow, Publishers of Ministry Defence SSSR, $1991.404 \mathrm{p}$.

4. Bobryshev A.N., Kozomazov V.N., Babin L.O., Solomatov V.I. Synergetics of Composite Materials. Lipetsk, NPO ORIUS Publ., 1994. 154 p.

5. Brady L.M., Ball R.C. Fractal Growth of Copper Electrodeposits. Nature, 1984, vol. 309, no. 5965, pp. 225-229.

6. Buchachenko A.L. Nanochemistry: a Direct Route to High Technologies of the New Century. Achievements of Chemistry, 2003, vol. 72, no. 5, pp. 419-437.

7. Edwards D.C. Polymer-filler Interaction in Rubber Reinforcement. J. Mater. Dci., 1990, vol. 25, no. 12, pp. 4175-4185.

8. Honeycombe R.W.K. The Plastic Deformation of Metals. Cambridge, Edwards Arnold Publ., 1968. 402 p.

9. Komarov B.A., Dzhavadyan E.A., Irzhak V.I., Ryabenko A.G., Lesnichaya V.A., Zvereva G.I., Krestinin A.V. Polymer Science, Series A, 2001, vol. 53, no. 6, pp. 897-905.

10. Kozlov G.V., Sanditov D.S. Anharmonic Effects and Physical-Mechanical Properties of Polymers. Novosibirsk, Nauka Publ., 1994. 261 p.
11. Kozlov G.V., Yanovskii Yu.G., Zaikov G.E. Particulate-Filled Polymer Nanocomposites. Structure, Properties, Perspectives. New York, Nova Science Publ., Inc., 2014. 273 p.

12. Kozlov G.V., Yanovskiy Yu.G., Zaikov G.E. Structure and Properties of Particulate-Filled Polymer Composites: The Farctal Analysis. New York, Nova Science Publ., Inc., 2010. 282 p.

13. Kozlov G.V., Yanovskiy Yu.G., Zaikov G.E. Synergetics and Fractal Analysis of Polymer Composites Filled with Short Fibers. New York, Nova Science Publ., Inc., 2011. 223 p.

14. Kozlov G.V., Zaikov G.E. Structure and Properties of Particulate-Filled Polymer Nanocomposites. Saarbrücken, Lambert Academic Publ., 2012. 112 p.

15. Kozlov G.V., Zaikov G.E. Structure of the Polymer Amorphous State. Utrecht, Boston, Brill Academic Publ., 2004. 465 p.

16. Malamatov A.Kh., Kozlov G.V., Mikitaev M.A. Reinforcement Mechanisms of Polymer Nanocomposites. Moscow, Publishers of D.I. Mendeleev RKhTU, 2006. 240 p.

17. Mikitaev A.K., Kozlov G.V., Zaikov G.E. Polymer Nanocomposites: Variety of Structural Forms and Applications. New York, Nova Science Publ., Inc., 2008. 319 p.

18. Shogenov V.N., Kozlov G.V. Fractal Clusters in Physics-Chemistry of Polymers. Nalchik, Polygraphservice and T, 2002.268 p.

19. Sumita M., Tsukumo Y., Miyasaka K., Ishikawa K. Tensile Yield Stress of Polypropylene Composites Filled with Ultrafine Particles. J. Mater. Sci., 1983, vol. 18, no. 5, pp. 1758-1764.

20. Weitz D.A., Huang J.S., Lin M.Y., Sung J. Dynamics of Diffusion-limited Kinetic Aggregation. Phys. Rev. Lett., 1984, vol. 53, no. 17, pp. 1657-1660.

21. Witten T.A., Rubinstein M., Colby R.H. Reinforcement of Rubber by Fractal Aggregates. J. Phys. II France, 1993, vol. 3, no. 3, pp. 367-383.

\section{АРМИРОВАНИЕ ДИСПЕРСНО-НАПОЛНЕННЫХ ПОЛИМЕРНЫХ НАНОКОМПОЗИТОВ АГРЕГАТАМИ НАНОЧАСТИЦ}

\section{Георгий Владимирович Козлов}

Старший научный сотрудник,

Кабардино-Балкарский государственный университет им. Х. М. Бербекова

I_dolbin@mail.ru

ул. Чернышевского, 175, 360004 г. Нальчик, Российская Федерация 


\section{Абдуллах Касбулатович Микитаев}

Доктор химических наук, профессор,

Кабардино-Балкарский государственный университет им. Х. М. Бербекова

I dolbin@mail.ru

ул. Чернышевского, 175, 360004 г. Нальчик, Российская Федерация

Аннотация. В работе была рассмотрена модель необратимой агрегации для теоретического описания процесса агрегации частиц нанонаполнителя в полимерных нанокомпозитах. Были выявлены основные факторы, влияющие на процесс агрегации наночастиц.

Ключевые слова: нанокомпозит, глобулярный наноуглерод, карбонат кальция, агрегация, эффектов межфазного, армирование. 